\title{
Meta-analysis study to evaluate the association of MTHFR C677T polymorphism with risk of ischemic stroke
}

\author{
P.A. Abhinand, M. Manikandan, R. Mahalakshmi, P.K. Ragunath* \\ Department of Bioinformatics, Sri Ramachandra University, Porur, Chennai - 600 116, India; PK Ragunath - Email: \\ abhinand.bioinfo@gmail.com; Phone: +919841351069; *Corresponding author
}

Received May 26, 2017; Accepted June 7, 2017; Published June 30, 2017

\begin{abstract}
:
Ischemic stroke is a condition characterized by reduced blood supply to part of the brain, initiating the ischemic cascade, leading to dysfunction of the brain tissue in that area. It is one of the leading causes of death and disability and is estimated to cause around 5.7 million deaths worldwide. Methyl tetra hydro-folate reductase (MTHFR) is a rate limiting enzyme in the methyl cycle which catalyzes the only biochemical reaction which produces 5, Methyl tetra hydro folate, the co-substrate for the re-methylation of homocystiene to produce methionine. MTFHR C677T is a common mutation of MTHFR and those homozygous for the MTFHR C677T produce a thermo-labile form of the protein with drastically reduced catalytic activity resulting in elevated plasma homocystiene levels - a common risk factor for cardiovascular diseases. However, the role of MTHFR C677T in ischemic stroke remains unclear. To evaluate this association, we carried out a meta-analysis of existing published studies, which included 72 studies involving 12390 cases and 16274 controls. The forest plot was made to evaluate the overall risk of the mutation in the etiology of Ischemic Stroke. The overall Odds- ratio of the study was found to be 1.319 for random effects model, revealing a $\sim 32 \%$ increased risk of Ischemic stroke in the presence of MTHFR C667T mutation compared to controls. Publication bias in the study was analyzed using funnel plot which revealed that only 7 studies out of the 72 contributed to publication bias. These 7 studies were excluded and Meta-analysis was repeated for 65 studies and overall odds-ratio was 1.306, which showed that there was a 30\% higher risk of Ischemic stroke in the presence of MTHFR C667T.
\end{abstract}

Keywords: MTHFR, MTHFR C677T, ischemic stroke, meta-analysis, folic acid

\section{Background:}

Stroke is a clinical condition characterized by poor blood flow to the brain resulting in cell death. It is of 2 major types: ischemic, due to lack of blood flow, and hemorrhagic, due to bleeding. Ischemic stroke is a clinical condition characterized by reduced blood supply to part of the brain, initiating the ischemic cascade, leading to dysfunction of the brain tissue in that area. The reduced blood flow can be caused by Thrombosis, Embolism, Systemic hypo perfusion or venous thrombosis. [1] Stroke is one of the leading causes of death and disability in India and world over. In 2005, ischemic stroke is estimated to cause around 5.7 million deaths worldwide and $87 \%$ of these deaths were in lowincome and middle-income countries. [2] The estimate adjusted prevalence rate of stroke range, 84-262/100,000 in rural and 334$424 / 100,000$ in urban areas. The incidence rate is $119-145 / 100,000$ based on the recent population based studies. [3] ISSN 0973-2063 (online) 0973-8894 (print)
Methyl tetra hydro folate reductase (MTHFR) gene which is located on chromosome 1 (1p36.3) encodes a $77 \mathrm{kDa}$ dimeric protein of the same name, which is a rate-limiting enzyme in the methyl cycle. [4] It catalyzes the only biochemical reaction, which produces 5, Methyltetrahydrofolate, the co-substrate for the remethylation of homocystiene to produce methionine. [5] MTFHR C677T ( $\mathrm{C} \rightarrow \mathrm{T}$ substitution at bp 677) is a common mutation of MTHFR causing an Alanine to Valine substitution at the 222nd position in the encoded protein product. People who are homozygous for the MTFHR C677T mutation produce a thermolabile form of the protein with drastically reduced catalytic activity resulting in elevated homocystiene levels in the plasma. [6, 7] Even a modest increase in plasma homocysteine has been known to be risk factor for cardiovascular diseases. [8, 9] However, its role in stroke remains unclear. Although most 


\section{BIOINFORMATION \\ Discovery at the interface of physical and biological sciences}

case-control studies suggest a positive association between elevated plasma homocysteine and stroke, nested case-control studies to establish such an association are rare and are limited by the availability of previous studies. [10]

Meta-analysis is a powerful statistical technique involving analysis of a large collection of analysis results from individual studies for the purpose of integrating the findings. [11, 12] It is a quantitative and formal epidemiological study design used to systematically assess the results from previous research to derive conclusions about that body of research. [13] We performed an updated systematic review and cumulative meta-analysis of available data and quantify the stroke risk associated with the 677T allele with a sufficient sample size to address these power limitations.

\section{Search Electronic databases - \\ PUBMED, Cochrane library and}

Google Scholar (until March 2012)

for all case-control studies

evaluating association between

MTHFR C67TT gene polymorphism

and ischemic stroke/NTD/Down

Syndrome in humans

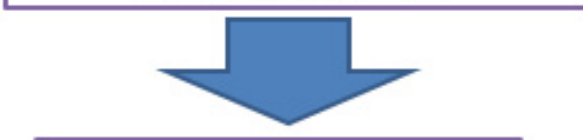

Evaluate HW-Equilibrium

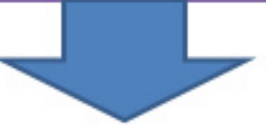

\section{Examine Heterogeneity using \\ Higgins I-square Test and} calculate OR

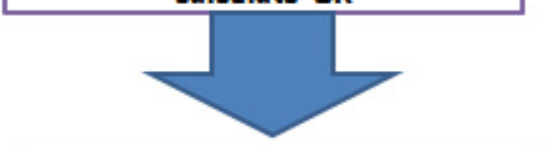

Analyze pooled ORs using the
random-effects model

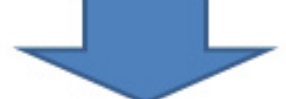

\section{Examine any publication bias \\ statistically by Begg's funnel plot and Egger's test}

\section{Eliminate duplicate records}

\section{Eliminate studies not fulfilling} inclusion criterion

Figure 1: Steps Involved in Meta-analysis to study the association of MTHFR C677T polymorphism with risk of Ischemic Stroke 


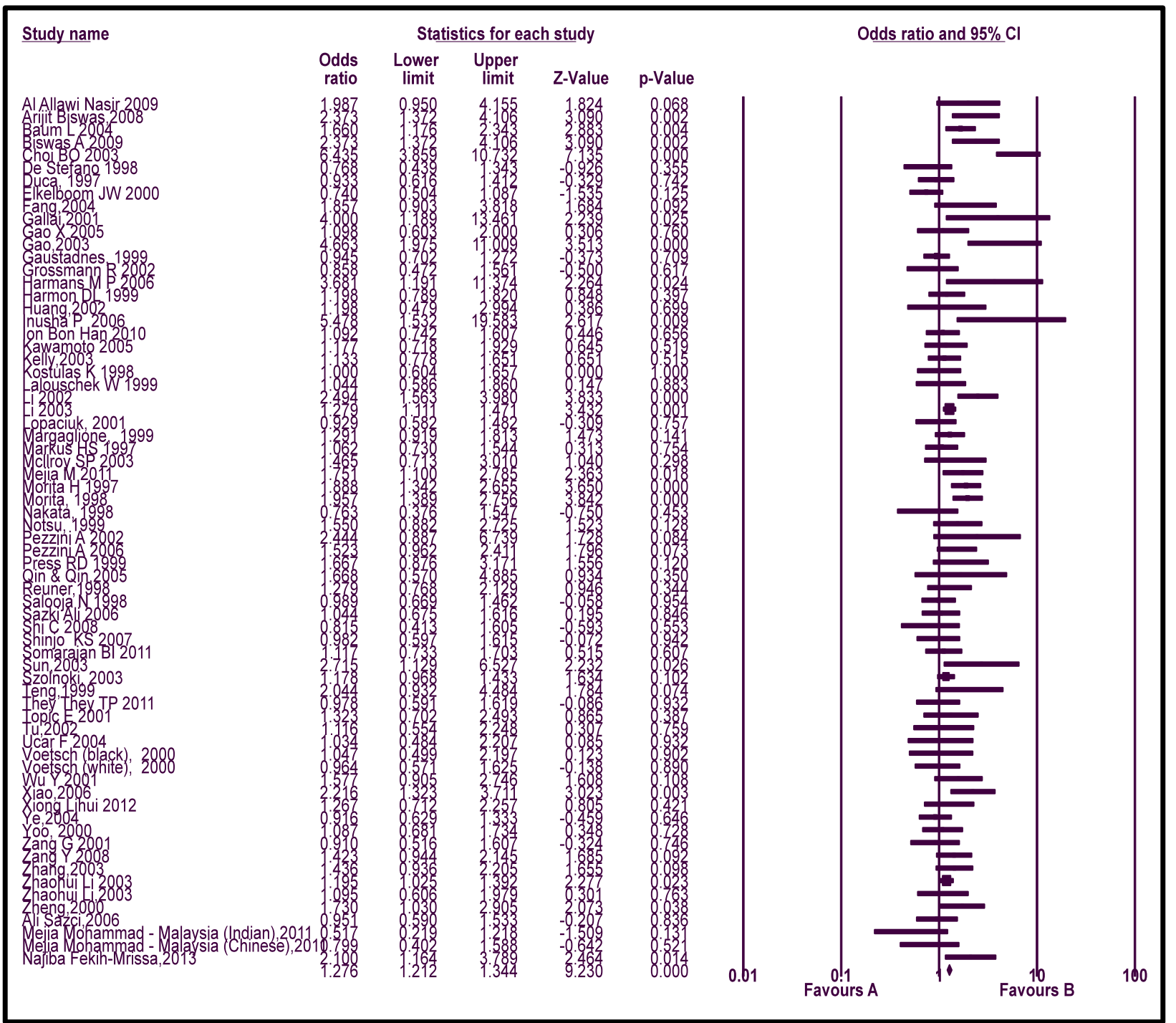

Figure 2: Forest plot and pooled ORs of risk from studies investigating MTHFR C677T polymorphism and ischemic stroke for Dominant model

\section{Methodology:}

Systematic Literature Survey:

Electronic databases (PUBMED, Cochrane library and Google Scholar) were searched until March 2012 for all case-control studies evaluating MTHFR C677T gene polymorphism and ischemic stroke in humans.

In PUBMED the following queries were used for enlisting all the eligible studies

(('M' OR ‘m') AND C677T AND ‘ I' AND ('H' OR 'h')

(('M' OR 'm') AND C677T AND ‘CI' AND ('H' OR 'h')

(('M’ OR ‘m') AND C677T AND ‘BI’ AND ('H' OR ’h')

$\mathrm{M}=$ Methylenetetrahydrofolatereductase; $\mathrm{m}=$ MTHFR; $\mathrm{I}=$ Ischemic Stroke; $\mathrm{CI}=$ Cranial infraction; $\mathrm{BI}=$ Brain Ischemia $\mathrm{H}$

= Homo sapiens; $\mathrm{h}=$ human

All published manuscripts including letters, previous metaanalyses, and abstracts were searched. The retrieved studies were examined thoroughly to assess their appropriateness for inclusion. The search results were limited to human. All languages were searched initially, but only articles in English language were selected. The references of all computer-identified publications were searched for any additional studies, and the MEDLINE option-related articles were used for all the relevant articles.

\section{Inclusion and Exclusion Criteria:}

Studies were included if: (a) study design was case-control and (b) had confirmed diagnosis of ischemic stroke with magnetic resonance imaging (MRI) or computed tomography (CT). A standardized data collection form was used for data extraction; this form mainly included the following content: (i) Name of the first author, year of publication, country, and racial descent; (ii) Demographics, number of cases and controls, and source of cases and controls; (iii) Distribution of genotypes and alleles; (iv) Hardy-Weinberg equilibrium 
Table 1: Characteristics of studies included in the meta-analysis with respective sample sizes

\begin{tabular}{|c|c|c|c|c|c|c|c|}
\hline Study Name & $\begin{array}{l}\text { Year of } \\
\text { Study }\end{array}$ & Origin & $\begin{array}{l}\text { Wild Type } \\
\text { Case (CC) }\end{array}$ & $\begin{array}{l}\text { Mutant Case } \\
(\mathrm{CT}+\mathrm{TT})\end{array}$ & $\begin{array}{l}\text { Wild Type Control } \\
\text { (CC) }\end{array}$ & $\begin{array}{l}\text { Mutant Control } \\
\text { (CT+TT) }\end{array}$ & $\begin{array}{l}\text { Hardy Weinberg } \\
\text { Equilibrium }\end{array}$ \\
\hline Al AllawiNasir & 2009 & Iraq & 26 & 44 & 27 & 23 & Yes \\
\hline Alluri RV & 2005 & India & 50 & 25 & 48 & 1 & Yes \\
\hline ArijitBiswas & 2008 & India & 67 & 53 & 90 & 30 & Yes \\
\hline Baum L & 2004 & China & 125 & 116 & 195 & 109 & Yes \\
\hline Biswas A & 2009 & India & 67 & 53 & 90 & 30 & Yes \\
\hline Choi BO & 2003 & Korea & 62 & 133 & 90 & 30 & Yes \\
\hline D. Arsene & 2011 & Romania & 37 & 30 & 17 & 43 & Yes \\
\hline De Stefano & 1998 & Italy & 28 & 44 & 65 & 133 & Yes \\
\hline Duca & 1997 & Italy & 62 & 118 & 74 & 151 & Yes \\
\hline Elkelboom JW & 2000 & Australia & 106 & 113 & 84 & 121 & Yes \\
\hline Fang, & 2004 & China & 15 & 39 & 40 & 56 & Yes \\
\hline Gallai & 2001 & Italy & 5 & 20 & 15 & 15 & Yes \\
\hline Gao X & 2005 & China & 30 & 70 & 32 & 68 & Yes \\
\hline Gao, & 2003 & China & 13 & 67 & 19 & 21 & Yes \\
\hline Gaustadnes, & 1999 & Denmark & 107 & 100 & 545 & 539 & Yes \\
\hline Grossmann R & 2002 & Germany & 73 & 20 & 141 & 45 & Yes \\
\hline Harmans M P & 2006 & Belgium & 4 & 19 & 62 & 80 & Yes \\
\hline Harmon DL & 1999 & Ireland & 74 & 100 & 86 & 97 & Yes \\
\hline Huang & 2002 & China & 11 & 28 & 16 & 34 & Yes \\
\hline Inusha P & 2006 & India & 23 & 9 & 56 & 4 & Yes \\
\hline Ion Bon Han & 2010 & Korea & 75 & 188 & 71 & 163 & Yes \\
\hline Kawamoto & 2005 & Japan & 33 & 64 & 91 & 150 & Yes \\
\hline Kelly & 2003 & North America & 102 & 141 & 91 & 111 & Yes \\
\hline Kostulas K & 1998 & Sweden & 76 & 50 & 76 & 50 & Yes \\
\hline Lalouschek W & 1999 & Austria & 38 & 58 & 39 & 57 & Yes \\
\hline $\mathrm{Li}$ & 2002 & China & 58 & 85 & 97 & 57 & Yes \\
\hline $\mathrm{Li}$ & 2003 & China & 520 & 1303 & 619 & 1213 & Yes \\
\hline Lopaciuk & 2001 & Poland & 51 & 49 & 117 & 121 & Yes \\
\hline Margaglione & 1999 & Italy & 53 & 149 & 326 & 710 & Yes \\
\hline Markus HS & 1997 & UK & 162 & 183 & 78 & 83 & Yes \\
\hline Mcllroy SP & 2003 & Ireland & 39 & 24 & 50 & 21 & Yes \\
\hline Mejia M & 2011 & Malaysia & 69 & 81 & 85 & 57 & Yes \\
\hline Mejia Mohammad & 2011 & Malaysia (Indian) & 25 & 17 & 19 & 25 & Yes \\
\hline Mejia Mohammad & 2011 & Malaysia (Chinese) & 33 & 39 & 25 & 37 & Yes \\
\hline Mejia Mohammad & 2011 & Malaysia (Malay) & 23 & 13 & 13 & 23 & Yes \\
\hline NajibaFekih-Mrissa & 2013 & Tunisia & 35 & 49 & 60 & 40 & Yes \\
\hline Pezzini A & 2002 & Italy & 9 & 22 & 18 & 18 & Yes \\
\hline Pezzini A & 2005 & Italy & 46 & 117 & 60 & 98 & Yes \\
\hline Pezzini A & 2006 & Italy & 51 & 123 & 60 & 95 & Yes \\
\hline Press RD & 1999 & USA & 56 & 80 & 28 & 24 & Yes \\
\hline Qin \& Qin & 2005 & China & 11 & 39 & 8 & 17 & Yes \\
\hline Reuner & 1998 & Germany & 37 & 54 & 85 & 97 & Yes \\
\hline Salooja N & 1998 & UK & 114 & 128 & 81 & 92 & Yes \\
\hline Sazki Ali & 2006 & Turkey & 52 & 68 & 115 & 144 & Yes \\
\hline Shi C & 2006 & China & 23 & 74 & 20 & 79 & Yes \\
\hline Shinjo KS & 2007 & Brazil & 55 & 72 & 54 & 72 & Yes \\
\hline Somarajan BI & 2011 & India & 137 & 70 & 129 & 59 & Yes \\
\hline Sun & 2003 & China & 8 & 53 & 25 & 61 & Yes \\
\hline Szolnoki & 2003 & Hungary & 415 & 452 & 386 & 357 & Yes \\
\hline Teng & 1999 & China & 12 & 50 & 26 & 53 & Yes \\
\hline They They TP & 2011 & Morocco & 48 & 43 & 95 & 87 & Yes \\
\hline Topic E & 2001 & Croatia & 25 & 31 & 64 & 60 & Yes \\
\hline $\mathrm{Tu}$ & 2002 & China & 24 & 45 & 25 & 42 & Yes \\
\hline Ucar F & 2004 & Turkey & 15 & 15 & 123 & 119 & Yes \\
\hline Voetsch & 2000 & Brazil (black) & 22 & 17 & 61 & 45 & Yes \\
\hline Voetsch & 2000 & Brazil (white) & 47 & 67 & 48 & 71 & Yes \\
\hline $\mathrm{Wu} \mathrm{Y}$ & 2001 & Japan & 23 & 54 & 92 & 137 & Yes \\
\hline Xiao, & 2006 & China & 49 & 113 & 49 & 51 & Yes \\
\hline XiongLihui & 2012 & China & 35 & 54 & 46 & 56 & Yes \\
\hline $\mathrm{Ye}$ & 2004 & China & 132 & 68 & 192 & 108 & Yes \\
\hline Yoo & 2000 & South Korea & 41 & 81 & 77 & 140 & Yes \\
\hline Zang G & 2001 & China & 40 & 62 & 37 & 63 & Yes \\
\hline Zang $\mathrm{Y}$ & 2008 & China & 49 & 196 & 74 & 208 & Yes \\
\hline Zhang & 2003 & China & 45 & 189 & 66 & 193 & Yes \\
\hline Zhaohui Li & 2003 & China & 389 & 931 & 610 & 1222 & Yes \\
\hline Zhaohui Li & 2003 & China & 29 & 71 & 34 & 76 & Yes \\
\hline Zheng & 2000 & China & 43 & 72 & 62 & 60 & Yes \\
\hline Ali Sazci & 2006 & Turkey & 42 & 50 & 115 & 144 & Yes \\
\hline
\end{tabular}




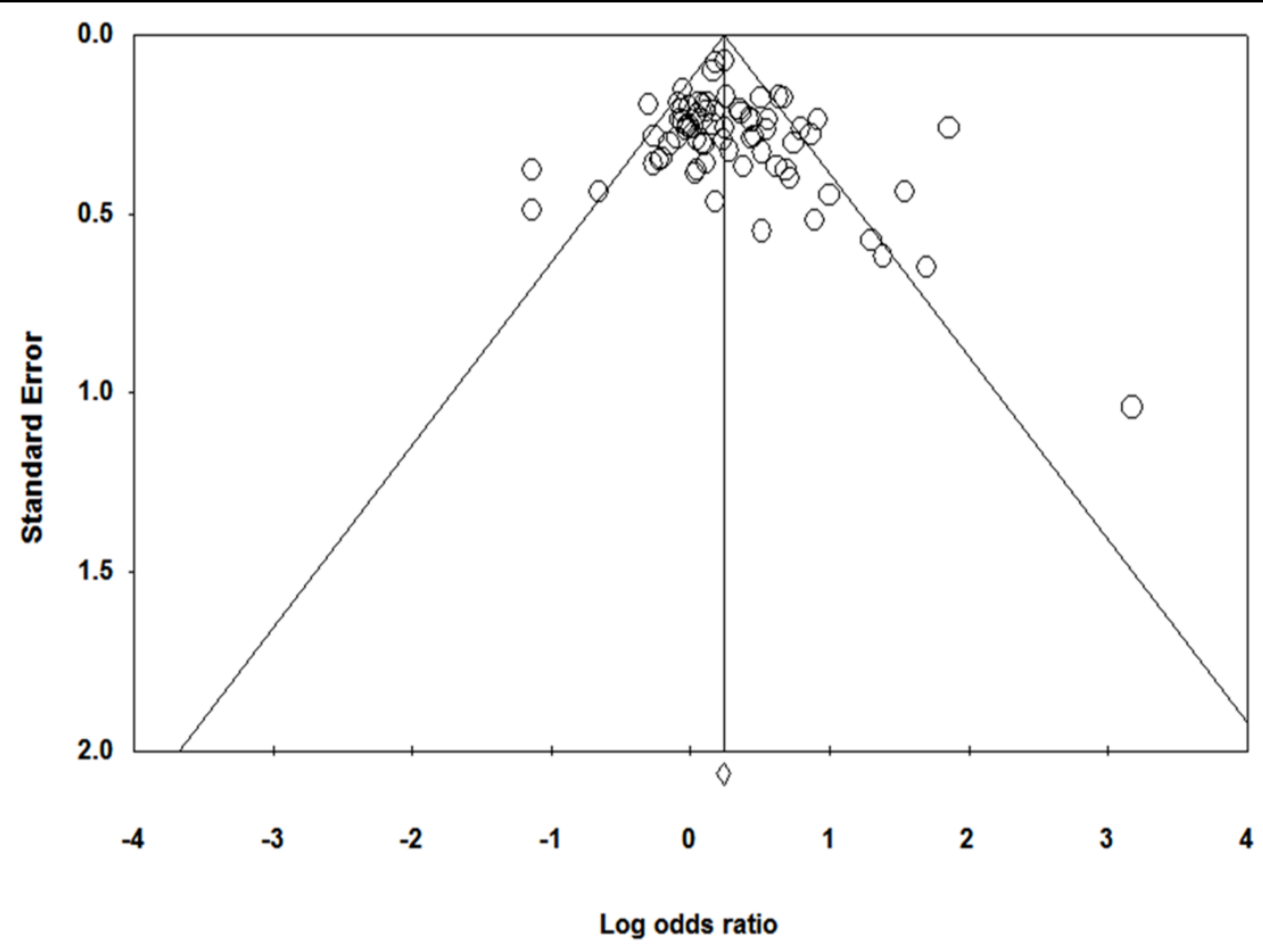

Figure 3: Funnel plot of Standard error by Log odds ratio for assessing publication bias

\section{Meta-Analysis:}

The Comprehensive Meta-Analysis Version 3.0 performed all statistical analyses. Two-sided $\mathrm{p}$ values less than 0.05 were considered statistically significant. For the control groups for each study, the observed genotype frequencies of the MTHFR C677T polymorphism were evaluated for Hardy-Weinberg equilibrium. The strength of the association between the MTHFR C677T polymorphism and Ischemic Stroke was assessed by the odds ratios (ORs) with 95\% CIs. The pooled ORs of Patients with Ischemic Stroke vs. Healthy controls were calculated for the dominant model (CT + TT vs. CC). The evaluation of the metaanalysis results included a test for heterogeneity, an analysis of the sensitivity, and an examination for publication bias. Considering possible heterogeneity between studies, $\mathrm{I}^{2}$ metric were conducted, $\mathrm{p}<0.10$ and $\mathrm{I}^{2}>50 \%$ were considered to indicate the existence of significant heterogeneity. [14] If the heterogeneity test result returned $\mathrm{p}>0.1$, the pooled ORs were analyzed using the random-effects model [15], or else, the fixed effects model was used. [16] Sensitivity analyses were also performed after sequential removal of each study. Lastly, Begg's funnel plot and Egger's test were used to examine statistically any publication bias $[\mathbf{1 7}, \mathbf{1 8}]$. The overall methodology is depicted in Figure 1

\section{Results \& Discussion:}

The current study investigated the association between risk of ischemic stroke and MTHFR C677T polymorphism. Study revealed that the presence of MTHFR C677T significantly increases the risk of ischemic stroke. Numerous studies have been carried out across the globe to determine the association between MTHFR C677T polymorphism and ischemic stroke; however, the association remains inconclusive. With an aim to accurately quantify this association, we carried out a meta- analysis of existing published studies, which included 72 studies involving 12390 cases and 16274 controls (Shown in Table 1). The forest plot was made to evaluate the overall risk of the mutation in the etiology of Ischemic Stroke. The overall Odds- ratio of the study was found to be 1.276 for fixed effect model and 1.319 for random effects model, which showed that there was a $\sim 32 \%$ increased risk of Ischemic stroke in the presence of MTHFR C667T mutation compared to controls. The Forest plot is depicted in Figure 2. The findings from the current meta-analysis study are in agreement with both the previously carried out meta-analyses on evaluating association between risk of ischemic stroke and MTHFR C677T polymorphism. The study concurs with results from Li et al. (2004) [19] which included 19 case-control studies involving 2223 cases and 2936 controls where this polymorphism was found to be potentially associated with the risk of ischemic stroke. [19] Our results also agree with the findings of Kumar et al. (2015) [20] comprising of 6310 patients and 8297 controls. [20] Publication bias in the study was analyzed using funnel plot, which revealed that only 7 studies out of the 72 contributed to publication bias. These 7 studies were excluded and Metaanalysis was repeated for 65 studies. The overall odds-ratio was found to be 1.306 that showed that there was a $30 \%$ higher risk of Ischemic stroke in the presence of MTHFR C667T mutation compared to controls.

\section{Conclusion:}

This current study is the largest meta-analysis consisting of 72 studies, carried out to evaluate the association between MTHFR C677T polymorphism and the risk of ischemic stroke. The study done showed that the polymorphism significantly increased $(\sim 30 \%)$ the risk of ischemic stroke. The study further suggests the importance of MTHFR genotyping for identifying patients 
susceptible for risk of ischemic stroke and for preventing and managing stroke cases. The study findings have a clear implication on health policy makers to enable increased intake of Levomefolic acid to reduce the risk of ischemic stroke. Bigger prospective studies with correction for multiple comparisons are essential for further validating the study findings.

\section{References:}

[1] Deb P et al. Pathophysiology 2010; 17(3): 197 [PMID: 20074922]

[2] Strong K et al. Lancet Neurol 2007; 6(2): 182 [PMID: 17239805]

[3] Pandian JD et al. J Stroke 2013; 15(3): 128

[4] Goyette P et al. Mamm Genome 1998; 9(8): 652 [PMID: 9680386]

[5] Födinger M et al. J Nephrol 2000; 13(1): 20 [PMID: 10720211]

[6] Frosst P et al. Nat Genet 1995; 10(1): 111 [PMID: 7647779]

[7] Kang YK et al. PediatrPathol 2014; 12(5): 717 [PMID: 1437884]
[8] Graham IM et al. JAMA. 1997; 277(22): 1775

[9] Bots ML et al. Arch Intern Med 1999; 159(1): 38 [PMID: 9892328]

[10] http://stroke.ahajournals.org/content/25/10/1924.short

[11] http://www.bmj.com/cgi/doi/10.1136/bmj.323.7303.42

[12] Stewart LA et al. Eval Health Prof 2002; 25(1): 76 [PMID: 11868447]

[13] Haidich AB et al. Hippokratia 2010; 14:29 [PMID: 21487488]

[14] http://doi.wiley.com/10.1002/sim.1186

[15] DerSimonian R et al. Control Clin Trials 1986; 7(3): 177 [PMID: 3802833]

[16] MANTEL N et al. J Natl Cancer Inst 1959; 22(4): 719 [PMID: 13655060]

[17] Egger M et al. BMJ 1997; 315(7121): 1533 [PMID: 9432252]

[18] Colin B. et al. J R Stat Soc Ser A 1988; 151:419

[19] P Li et al. Gene 2013; 535(2): 359 [PMID: 24140489]

[20] Kumar et al. Neurol Res. 2015; 37(7): 568 [PMID: 25591425]

Edited by $P$ Kangueane Citation: Abhinand et al. Bioinformation 13(6): 214-219 (2017) License statement: This is an Open Access article which permits unrestricted use, distribution, and reproduction in any medium, provided the original work is properly credited. This is distributed under the terms of the Creative Commons 